\title{
Logophoricity, Highlighting and Contrasting: A Pragmatic Study of Third-person Reflexives in Chinese Discourse
}

\author{
Lijin Liu \\ Editorial Office, Journal of Guangdong University of Foreign Studies, GDUFS \\ 2 Baiyun Avenue (North), Guangzhou 510420, China \\ E-mail: liulj@mail.gdufs.edu.cn \\ Ning He \\ Division of Vocational Rehabilitation, State of Missouri \\ 901 Progress Drive, Farmington, MO 63640, USA \\ E-mail: newpilot01@hotmail.com
}

Received: December 12, 2011

Accepted: December 30, 2011

Published: March 1, 2012

doi:10.5539/ells.v2n1p69

URL: http://dx.doi.org/10.5539/ells.v2n1p69

The research is sponsored by the Social Science Funds Project of the MOE, China. No. 10YJA740063

\begin{abstract}
This paper, in light of the notion of 'minimal discourse-internal protagonist', sets out to formulate as its analytic framework a pragmatic principle governing anaphora patterns and then explores the functions of third-person reflexives in Chinese discourse. The findings are in order. First, in Chinese, simplex reflexives are basically logophoric, whereas complex reflexives serve primarily to highlight and contrast discourse entities. Secondly, there are two types of constructions in Chinese in terms of anaphoric production: one is known as single-fold anaphora and the other as dual or multifold anaphora. And thirdly, our proposed pragmatic principle can very well capture the uses of reflexives in Chinese discourse.
\end{abstract}

Keywords: Reflexives, Anaphoric interpretation, Anaphoric production, Pragmatic principle

\section{Introduction}

In the light of the notion of 'minimal discourse-internal protagonist' (henceforth MDP for short) as proposed in e.g. Zribi-Hertz (1989) and Sells (1987), this study is to formulate a pragmatic principle controlling anaphora patterns in order to describe the functions of third-person (Note 1) long-range reflexives (hereafter 'reflexives' for the sake of simplicity) in Chinese discourse.

Here the MDP is, on our part, defined as a most prominent, vital entity in a given (fragment of) discourse, which is dominant in the unfolding of the discourse. As well, it is viewed as a semantic-discourse role and the deictic center of reflexives (see (8a-(ii)) below for a clear definition). The anaphoric relationship thus established between a reflexive (anaphor) and the MDP (antecedent) is known as logophoricity (Sells 1987) or logophora (Baltin 2003, Huang 2008) or logophoric anaphora (Reinhart and Reuland 1991: 312). For example, in (1) below, Chinese "ziji” in the second clause refers back to the MDP "Mingzi" in the first clause, a sort of typical logophoric anaphora. And in English, as argued in Reuland 2009, reflexive pronouns can also have logophoric uses as manifested in (2): himself in the second sentence takes as its antecedent the MDP John in the first sentence.

$\begin{array}{lllllll}\text { (1) Keshi Mingzi } & \text { zhidao gugu } & \text { hen shili, } & \text { ziji } i_{1} & \text { you qiong, } \\ \text { but } & \text { Mingzi } & \text { know aunt } & \text { very snobbish self } & \text { yet poor } \\ \text { Suoyi yizhi } & \text { bugan tiqi } & \text { qinshi lai. (Xu Y. 2004) } & & \\ \text { therefore all the while } & \text { afraidmention marriage PA } & & \end{array}$

(But Mingzi $i_{1}$ knew that his aunt was snobbish and he ${ }_{1}$ was very poor, therefore he had been all the while afraid to mention the marriage.)

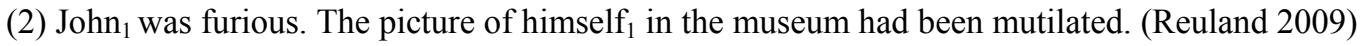


Previous approaches, 'more traditional' to say so, like what was called 'subject orientation' analysis as seen in earlier syntactic literature (Huang and Tang 1991, Battistella and Xu 1990) cannot deal with cases where the antecedent comes in non-subject position, such as objective or attributive position. Witness the examples in (3) below: anteceded "ta" (him) in (3a-b) and "Xiaoming" in (3c) are not subjects, refuting the subject-orientation approach; however, it is quite OK to treat them as MDP entities, which justifies an alternative account, say, an MDP-oriented one, to a huge extent, as will become more evident in the ensuing text.

(3) a.
Zhe jian shi
gaosu
ta $_{1} \quad$ ziji $_{1}$ yiqian de xiangfa buyiding dui.
this CL matter tell him self former MM idea
may not right (Xu L. 1997)

(This matter told $\operatorname{him}_{1}$ that his ${ }_{1}$ former idea may not be right.)

$\begin{array}{lllllll}\text { b. Zhe jian shi } & \text { shi } & \text { ta }_{1} \text { renshi } & \text { dao } & \text { ziji } i_{1} \text { yiqian } & \text { de xiangfa } & \text { buyiding dui. (ibid.) } \\ \text { this CL matter } & \text { make } & \text { him realize } & \text { PA self former } & \text { MM idea } & \text { may not right }\end{array}$

(This matter made him 1 realize that his ${ }_{1}$ former idea may not be right.)

$\begin{array}{cllll}\text { c. Mama } \text { biaoyang } & \text { le } \text { ziji }_{2 / 1} \text { shi } & \text { Xiaoming }_{2} & \text { hen gaoxing. (Huang 1994: 190) } \\ \text { Mum praise } & \text { AM self make } & \text { Xiaoming } & \text { very happy }\end{array}$

(That Mum praised him $_{2} /$ herself $_{1}$ makes Xiaoming 2 very happy.) (Huang 1994: 190)

In the next section we will propose as the analytic framework a pragmatic principle governing anaphora patterns in Chinese discourse, hinging on the concept of MDP.

\section{A pragmatic Principle}

We have to describe, beforehand, the semantic strength and/or informativeness of Chinese reflexives, whereby a semantic hierarchy of reflexive versus pronoun is postulated to show their distinct semantic features. In terms of reflexive pronouns, there are two types in Chinese: simplex and complex, namely "ziji" and "Pr-ziji". The semantic information of both types of reflexives and that of pronoun in Chinese are in order below.

(4) General semantic representation of Chinese third-person reflexive

$\mathrm{W}$

$\mathrm{NP}[\sim[1,2],\{\mathrm{Sg} / \mathrm{Pl}, \log , \mathrm{Em}\}]$

$\left[\mathrm{x}_{\mathrm{i}}\right]\left[\mathrm{x}_{\mathrm{i}}=\mathrm{P}\right]$

(5) a. Semantic representation of Chinese "ziji"

ziji

$\mathrm{NP}[\sim[1,2],\{\mathrm{Sg} / \mathrm{Pl},+\log , \pm \mathrm{Em}\}]$

$\left[\mathrm{x}_{\mathrm{i}}\right]\left[\mathrm{x}_{\mathrm{i}}=+\mathrm{P}\right]$

b. Semantic representation of Chinese "Pr-ziji"

Pr-ziji

$\mathrm{NP}[\sim[1,2],\{\mathrm{Sg} / \mathrm{Pl}, \pm \underline{\mathrm{L}} \mathrm{og},+\mathrm{Em}\}]$

$\left[\mathrm{x}_{\mathrm{i}}\right]\left[\mathrm{x}_{\mathrm{i}}= \pm \mathrm{P}\right]$

(6) General semantic representation of Chinese third-person pronoun

$\mathrm{W}$

$\mathrm{NP}[\sim[1,2],\{\mathrm{Sg} / \mathrm{Pl},-\mathrm{Log},-\mathrm{Em}\}]$

$\left[\mathrm{x}_{\mathrm{i}}\right]\left[\mathrm{x}_{\mathrm{i}}=-\mathrm{P}\right]$

Key to the symbols/numbers: $\mathrm{w}=$ reflexive (or pronoun); $\sim=$ negation of; $1=$ first person pronoun; $2=$ second person pronoun; $\mathrm{Sg}=$ singular; $\mathrm{Pl}=$ plural; $\mathrm{Log}=\operatorname{logophoric} ; \mathrm{Em}=$ emphatic; $\mathrm{x}_{\mathrm{i}}=$ entity referred to by w (e.g. reflexive); $\mathrm{P}=\mathrm{NP}$ encoding the protagonist; $+=$ obligatorily; $\pm=$ optionally; $-=$ lack or deprivation of (a feature).

As a reference frame, the semantic representation of Chinese pronoun is given in (6) (Note 2). So based on the descriptions above of semantic information, a semantic hierarchy of Chinese reflexive vs. pronoun (Pr for short) may be postulated in (7).

(7) ziji $=/>$ Pr-ziji $>\operatorname{Pr}$

The scale in (7) says that Chinese "ziji" may be understood as semantically tantamount to "Pr-ziji" in that generally 
the former is obligatorily logophoric while the latter obligatorily emphatic. On the other hand, "ziji" is deemed semantically stronger than "Pr-ziji" in that it contributes much more to discourse anaphora resolution, to the extent that it may be given more weightings due to its rich logophoricness. This greater weighting has proved to be true by the highly frequent occurrences of "ziji" in Chinese written discourse (Liu 2008a: 43).

We now propose a pragmatic principle regulating ad hoc the anaphoric and/or logophoric uses of Chinese reflexives as the analytic framework of this paper, as in (8).

(8) A pragmatic principle of discourse anaphora

a. Interpretation maxim (Note 3)

(i) In Chinese, a reflexive in a given (fragment of) discourse is generally understood as referring to the MDP, unless the particular situations in the discourse domain (e.g. co-occurrence of two or more contrasting items or speaker intending otherwise) prevent and/or alter this reading.

(ii) The MDP refers in that case to a proximate, prominent entity which is backward/left (or forward/right) accessible to the reflexive in a portion of the discourse and read as logophoric; and it is encoded as an NP or a conjoined NP.

\section{b. Production maxim}

In Chinese, where "ziji", "Pr-ziji" and Pr can all serve to create discourse anaphora, the speaker is supposed to prioritize "ziji" to encode logophora for the purpose of saving readers' time for discourse understanding, unless:

(i) "Pr-ziji" is required by the discourse condition (or speaker's subjective intention) to prioritize for producing strongly contrastive/emphatic constructions; or

(ii) Pr is only permitted by the discourse condition (or speaker's obligatory consideration) to produce an objective domain of discourse; (Note 4) or

(iii) Supplementary maxim: Where "ziji", "Pr-ziji" and Pr serve to produce two or more than two anaphoric chains, one is supposed to use "ziji" (and/or "Pr-ziji") to refer to MDP and use "Pr-ziji" and/or Pr to refer to other entities.

As suggested in (8b), the aforesaid principle needs to have additional constraints to become relatively perfect. According to Zribi-Hertz (1989), the use of English reflexive is in immediate connection with the narrative point of view: a subjective domain of discourse is narrated from the internal protagonist's perspective, while an objective one from the observer's perspective. Consider:

(9) Everything was full of the stir, the potency, the fecundity of spring.

Suddenly he said aloud: 'Possessiveness is the devil.'

Maggie $_{1}$ looked at him. Did he mean herself $f_{1}$-herself $f_{1}$ and the baby? (Zribi-Hertz 1989)

(10) The music made her ${ }_{1}$ think of her life as it seldom did; it exalted her $1 /$ *herself $_{1}$. (ibid.)

In (9), herself comes within the boundary of the MDP's point-of-view domain; that is, the (minimal) domain of discourse where the reflexive occurs is subjective and thus is transparent for it to create long-range anaphora or logophora. In (10), however, herself comes outside the boundary of the MDP's perspective, and this domain of discourse is objective and opaque so that the reflexive is not in a position to encode logophora, and instead, it entails therein the use of a pronoun characterized by [-Log] to establish discourse coherence.

For convenience, we quote and recompose in (11) part of Zribi-Hertz's (1989: 714) definition of subjective against objective domain of discourse and its restriction on reflexives, which count as additional constraints to the pragmatic principle in (8):

(11) a. A domain of point of view (DPV) consists of a clause category, which amounts to any phrase of subject-predicate structure, including zero-subject structure;

b. A DPV is subjective, where it contains a discourse-internal protagonist and the event or state is narrated from its point of view; and a DPV is objective, where it does not contain a discourse-internal protagonist and the event or state is described as it stands in the reality from the observer's point of view;

c. A DPV is opaque, where it involves an independent, objective narrative point of view; otherwise, it is transparent.

As noted in (8b), in anaphoric production the subjective and objective DPV may be occasionally predicated on the speaker's consideration: a pronoun is used where a reflexive might have been used, and vise versa. In (9), for instance, herself can be replaced by her. Under some circumstances, nonetheless, the speaker has to describe the event or state from the observer's perspective, excluding the possibility of use of reflexive, as in (10). This 
phenomenon occurs, too, in Chinese discourse, as in (12) below, which speaks volumes for the fact that the constraints stated in (11) work equally well on Chinese reflexives.

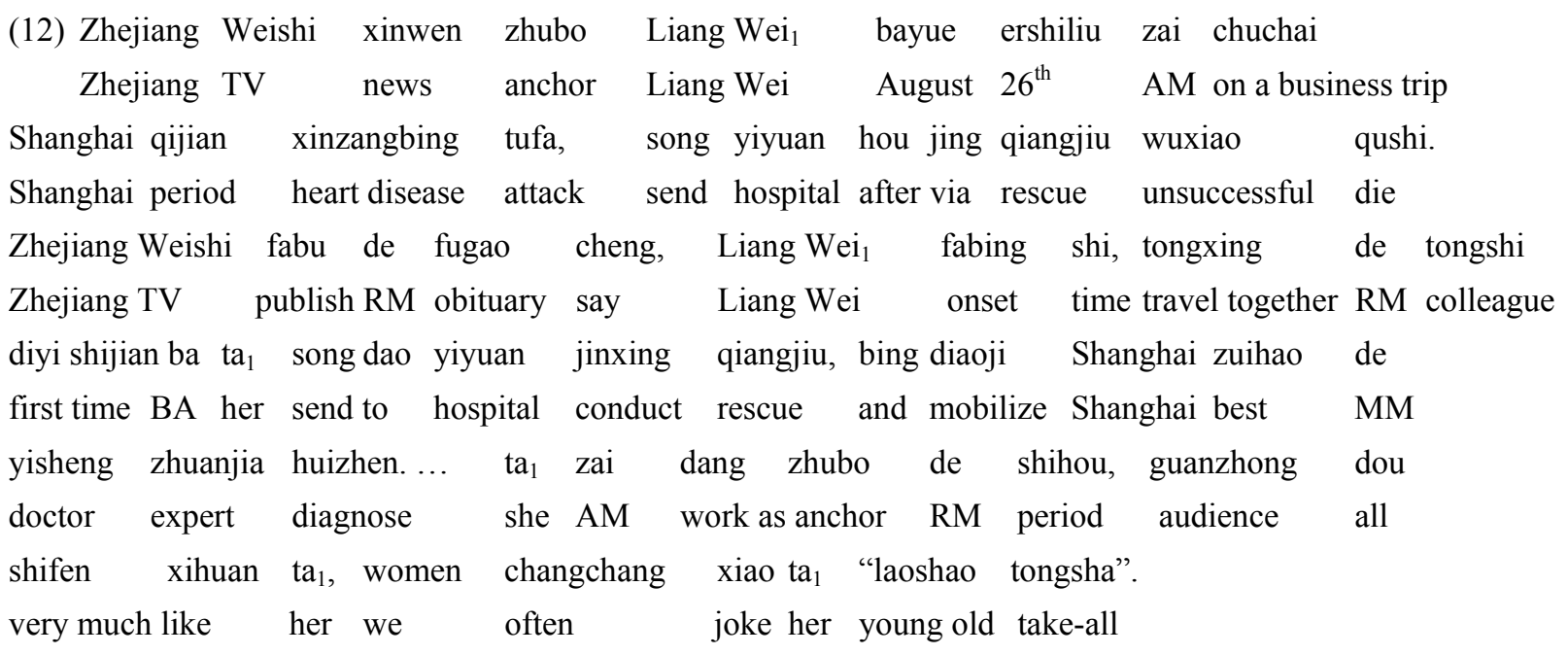

(Liang $\mathrm{Wei}_{1}$, a news anchor from Zhejiang TV, suffered a heart attack while on a business trip to Shanghai on August $26^{\text {th }}$; and died after she had been sent to the hospital for rescue. Zhejiang TV published an obituary notice, saying that when Liang $\mathrm{Wei}_{1}$ was at the onset of the disease, her colleagues travelling together sent her ${ }_{1}$ to the

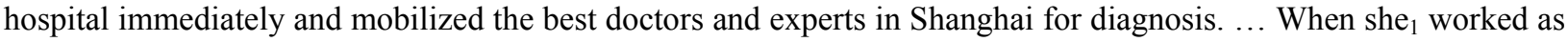
a news anchor, she ${ }_{1}$ was very much liked by the audience, so that we often joked about her ${ }_{1}$ "taking all young and old".)

Discourse (12) is extracted from a Chinese news report carried in The Southern Metropolis Daily on August 30, 2009 , where clearly the four occurrences of the pronoun "ta" cannot be replaced by a reflexive such as "ziji" or "taziji", since the DPV in the discourse established by a subject NP, say, "tongshi" (colleagues) or "women" (we), is opaque for a reflexive pronoun (Note 5).

\section{Interpretation of Reflexives in Chinese Discourse}

In what follows, we'll account for the functions of reflexives in Chinese discourse in accordance with the above principle. Exemplar analysis shows that Chinese simplex and complex reflexives differ from one another in discourse in respect of logophoric use, semantic emphasis and/or discourse prominence.

\subsection{Chinese Simplex Reflexive}

Without morphologically logophoric pronouns as in some African languages, Chinese is not counted among the "pure" logophoric languages as listed in Culy (1994, cf. Huang 2000: 176). But as far as its referential use is concerned, "ziji" suffices for being a logophor in Chinese. Huang (1994: 188-198) once gave a detailed description of the uses of "ziji" in logo-centric domain, created by triggers such as speech, epistemic, psychological, and perceptional verbs. Based on our observation, "ziji”" plays a similar, primary role in both logophoric domain and ordinary indirect discourse, referring to the MDP; and as a consequence it may well be defined as a logophor. The semantic features it carries are given in (5a): obligatorily logophoric, and optionally emphatic or contrastive. Compare:

$\begin{array}{clll}\text { (13) a. Hung-chien } & \text { xiangxin } & \text { Su Wen-wan yiding } & \text { jiayou jiajiang, shuo ziji } i_{1} \text { yinyou } \\ \text { Hung-chien } & \text { believe } & \text { Su Wen-wan surely } \\ \text { exaggerate say self lure } & \text { her } \\ \text { wen ta, zhunbei } & \text { ju shi fanbo. (Note 6) } & & \\ \text { kiss her be prepared } & \text { with fact } \text { counter } & & \end{array}$

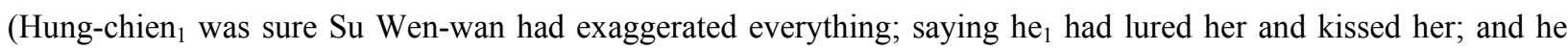
was prepared to counter lies with facts.)

$\begin{array}{cllllll}\text { b. Su Xiaojie } & \text { zhidao ta zai kan ziji, hui lian dui ta weixiao, Hung-chien } \\ \text { Su Xiaojie know he AM look at self turn face to him smile } & \text { Hung-chien } \\ \text { yao dikang zhe meili } & \text { de juexin, } & \text { xiang chushui } & \text { de yu, } \\ \text { wantresist this seductive force MM determination like } & \text { out-of-water } & \text { RM fish }\end{array}$


tou wei zai di shang paidong, keshi zhengzha bu qi.

head tail on ground LOC flap but jump up not PA

(She ${ }_{1}$ knew he had his eyes on her ${ }_{1}$ and turned to smile at him. His determination to resist this seductive force was like a fish out of water which flaps its head and tail about on the ground but can't get anywhere.)

(14) a. San Xiangu ${ }_{1}$ jian Er Zhuge laopoyijing bugu le ming, ziji $1_{1}$ xian danqie le jifen,bu gan

Third Fairy see Blacky's wife really ignore PA life, self first frightenedPA a bit not dare

lian zhan, shao nao le yihui, zhengtuo chulai jiu zou le.

keep quarrelingless quarrel PA a while break away at once leave AM

(When Third Fairy saw that Blacky's wife was really out for her blood, she ${ }_{1}$ became a bit frightened and broke away.)

b. $\mathrm{Ta}_{1}$ ben xiang zao gei Xiaoqin zhaoge pojia tui chumen qu,

she originally want early for Xiaoqin get CL boyfriend's family get her out of house PA

keshi yinwei ziji ${ }_{1}$ mingsheng bu zheng, chabuduo dou bu yuanyi gen ta jieqin.

But because self reputation not good almost all not want with her become related.

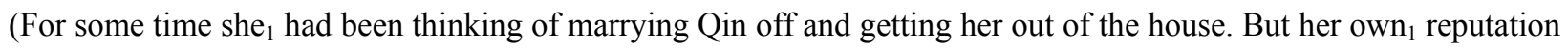
was so bad; no family wanted to become related to her.)

(15) a. Alexander ${ }_{1}$ de hushing yue lai yue xiang, 'te-lu' yisheng, ba ziji $_{1}$ xiaxing le:

Alexander MM snoring more and more loud, 'te-lu' snoring BA self wake AM

"Shui dahu laizhe?"

who snore AU

(Alexander's snoring grew so loud that it woke him 1 up; startled, he blinked, "Who's that?")

$\begin{array}{llllllll}\text { b. Zhe } & \text { zhen } & \text { rang } & \text { Xiangzi } & \text { de } \text { xin tiao } & \text { de kuai le xie! Zhen yao } \\ \text { this } & \text { really } & \text { make Xiangzi MM heartthump } & \text { AU fast PA a bit really if } \\ \text { cou } & \text { shang } & \text { san si shi } & \text { kuai, zai jiashang } & \text { Liu Siye } & \text { shouli na } \\ \text { collect } & \text { PA } & \text { thirty-forty } & \text { CL again plus } & \text { Fourth Master Liu in-hand that } \\ \text { sanshi duo, he ziji } & \text { xianzai you de na ji kuai, } & \text { qibu jiushi bashi lai de? } \\ \text { thirty overand selfnow } & \text { have RM that a few CL } & \text { wouldn'tjust eighty over PA }\end{array}$

(These words made his ${ }_{1}$ heart thump. He thought that if thirty or forty yuan could be collected from such a group, together with the thirty yuan kept by Fourth Master Liu and the little bit of money he himself $f_{1}$ had, that would come to over eighty dollars, wouldn't it?)
(16) a. Zhe zhong taidu shi
$\mathrm{ta}_{1}$ zhi gu
ziji $_{1}$ de shenghuo, ba yiqiehuohuan zainan
this CL attitude make
him only think
self MM livelihoodBA all calamities

dou fangzai nao hou.

all put out of mind

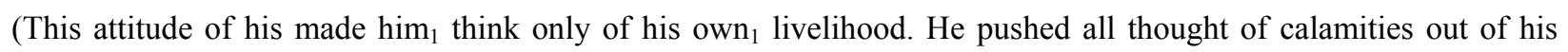
mind.)

b. Sun Xiaojie de lianhong huran shi ta xiangqi zai Faguo shi

Sun Xiaojie MM blushing face suddenly remind him think of in France time

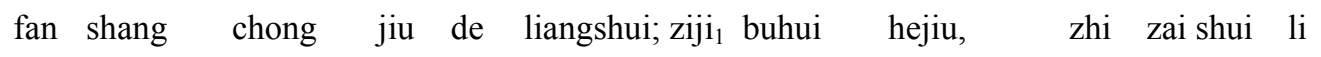

rice LOC add wine RM cold waterself cannot drink just in water LOC

chong yidiandian hongjiu, chang kan zhe hong yeti zai bai yeli li

add a little redwine often watch this red liquid in white liquid LOC

fanbu-aidai, zuochu yunwu zhuangtai...

diffuse turn into nebulous state 
(Miss Sun's blushing face suddenly reminded him 1 of the cold water on the tables in France for fixing drinks. Since he ${ }_{1}$ couldn't drink, he would just add a little red wine to the water, watching the red liquid diffuse in the white liquid. ...)

Examples of (13a-b) are two logophoric constructions triggered by the epistemic verbs "xiangxin" (believe) and "zhidao" (know); and there the reflexives come in the object clause. By (8a), the reflexives in these two discourses are understood as referring to MDP entities: in (13a) "ziji" is coreferential with "Hung-chien", encoded as matrix subject; and in (13b) it is coreferential with Miss Su, which is encoded also as matrix subject.

All examples in (14a)-(16b) are what can be called ordinary narrative discourses without logophoric verbs or triggers, in each of which the reflexive has to be understood by (8a) to refer to the MDP in question as well. In (14a-b) the MDP entity, encoded as subject of the first sentence, is naturally the most prominent noun phrase, so the two "ziji" are construed by (8a) as coreferential with "San Xiangu" (Third Fairy) and "ta" (she) respectively. Note that in (14b) "Xiao Qin" intervening between the reflexive and its antecedent does not invalidate long-distance anaphora, sufficing to indicate the logophoric role "ziji" plays in discourse.

In (15a), "Alexander" the MDP is encoded as attributive of the matrix subject; in (15b), "Xiangzi" the MDP is encoded as attributive of the embedded subject; and both are the prominent entity accessible to "ziji" in the discourse.

In (16a-b), both MDPs are actualized by the pronoun "ta" (he) in object position. In (16a), "ta" is the only eligible antecedent of "ziji"; and as an attribute, the reflexive here is not a so-called local anaphor since it may be replaced by "ta". Viewed from the encoder/speaker, however, the choice of "ziji" fits in with production maxim (8b): where reflexive "ziji" and pronoun "ta" can both serve to establish discourse anaphora, the speaker is supposed to prioritize the reflexive to encode logophora to save time for discourse understanding. And the anaphora pattern in (16b) is in a long sentence or cross-sentence construction and "ziji", which acts as subject of the second clause, is interpreted as coreferential with "ta", the object of the verb "shi", (reminded) in the preceding sentence.

\subsection{Chinese Complex Reflexive}

As seen in (5b), the semantics of complex reflexive "Pr-ziji" differs from that of simplex reflexive "ziji" in that its logophoric use is optional, not obligatory; but its emphatic use is obligatory. Instantiations in discourse show that "Pr-ziji" may be analyzed as an emphatic or intensive expression of pronoun, serving primarily to highlight and contrast entities in the establishment of discourse coherence (Baker 1995). Both uses of "tamenziji" (themselves) in (17) below, for example, can be understood as an intensive item of "tamen" (them), not referring to "shou guo hai de ren" (peasants who suffered a lot), but referring to "ta liangren" (they both) nearby, with "minbing" (militiamen) and "minfu" (villagers) intervening in between. Similarly in (18) "taziji" (herself) refers back to "San Nainai" (Third Daughter-in-law), with "gongpo" (her father-in-law) intervening in between, and the narrator makes use of "taziji" to highlight the entity referred to; however one can substitute "ziji" for it so as to reduce its salience or emphaticness and suggest its logophoric reference.

$\begin{array}{llllllllllll}\text { (17) Ta } & \text { yi shuo kaile tou, } & \text { xuduo } & \text { shou } & \text { guo hai } & \text { de } & \text { ren } & \text { ye dou } & \\ \text { he } & \text { once begin speaking up } & \text { many } & \text { suffer } & \text { AM } & \text { harm } & \text { RM people } & \text { also all } & \\ \text { qiangzhe shuo } & \text { qilai: you } & \text { gei } & \text { tamen hua } & \text { guo qian } & \text { de, you } & \text { bei } \\ \text { try first } & \text { speak } & \text { PA some } & \text { PM } & \text { them blackmail } & \text { AM money PA } & \text { some } & \text { PM } \\ \text { tamen } & \text { bizhe } & \text { shang } & \text { guo diao } & \text { de; ta liangren } & \text { hai pai shang } & \text { minbing } & \\ \text { them } & \text { drive } & \text { commit } & \text { AM suicide } & \text { PA they both } & \text { also send PA } & \text { militiamen }\end{array}$

gei tamenziji $i_{1}$ ge chai, bo shang minfu gei tamenziji $i_{1}$ chu di;

for themselves cut firewood order PA villager for themselves hoe field

fu shou liang, si pai kuan, qiangpo minbing kun ren.

confiscate grain impose taxes order militiamen arrest people

(That broke the ice. Peasants rose one after another to expose the wickedness of Xing and Wang-blackmail, driving people to suicide. ... They ${ }_{1}$ sent militiamen out to cut their ${ }_{1}$ firewood; they ordered villagers to hoe their $_{1}$ fields. They confiscated grain, imposed taxes, and used the militia as their private police.)
(18) San Nainai
qiao gongpo yao
taziji
lingzhe haizi,
yi kou
Third Daughter-in-law
see father-in-law
expect
herself look after baby
one $\mathrm{CL}$ 
menqi zhang de duzi dou jianjian da le, chi dongxi mei weikou,

pent-up resentment swell AU stomach evengradually big PA eat things have no appetite

sizhi fali, qing yi fu yao, tongshi AhHsiung zhi neng you popo

limbs grow weak call doctor take medicine meanwhile Ah Hsiung only can PM grandma

bangzhe dialing.

help take care of

(Seeing that her father-in-law expected her ${ }_{1}$ to take care of the baby herself ${ }_{1}$, Third Daughter-in-law's $s_{1}$ pent-up resentment swelled and so did her stomach, while her appetite diminished and her limbs grew weak. The doctor was called in and she was given some medicine. Meanwhile Ah Hsiung became the sole charge of his grandmother.)

By contrast, in the following discourses "Pr-ziji" and its antecedent are separated obviously farther away: the two reside in different sentences.

(19) Lao Tong Bao ${ }_{1}$ suiran bu hen jide zufu shi zenyang "zuoren", dan fuqin de qinjian Old Tong Bao although not very recall grandpa be what sort of man but father MM diligence zhonghou,ta ${ }_{1}$ shi qinyan kanjian de; taziji $i_{1}$ ye shi guiju ren, ... honesty he just with his own eyes see PA himself also be respectable man

(Although Old Tong $\mathrm{Bao}_{1}$ couldn't recall what sort of man his grandfather was, he $\mathrm{e}_{1}$ knew his father had been hardworking and honest $-\mathrm{he}_{1}$ had seen that with his own eyes. Old Tong Bao himself $f_{1}$ was a respectable person; ...)

(20) Lao Tong $\mathrm{Bao}_{1}$ tai qi ta na jiaohuang de zhoulian, kunao de wang zhe

Old Tong Bao raise PA his that sallow MM shrunken face, bitterly MM gaze AM ta mianqian de na tiao he, he li de chuan, yiji liangan de sang di. his front $\mathrm{MM}$ that $\mathrm{CL}$ river river LOCMM boat and both bank MM mulberry field Yiqie dou he ta ${ }_{1}$ ershi duo sui shi chabuliaoduoshao, ran'er "shijie" daodi all entirely and he twenty over year time almost the same but world anyway bian le. Taziji $1_{1}$ jia ye yao changchang ba zaliang dang fan chi yi tian. change AM his own family also have to often BA pumpkinas rice eat one day

(Old Tong $\mathrm{Bao}_{1}$ raised his shrunken face, scorched by years of hot sun to the color of dark parchment. He gazed bitterly at the canal before him, at the boats on its waters, at the mulberry trees along its banks. All were approximately the same as they had been when he ${ }_{1}$ was twenty. But the world had changed. His ${ }_{1}$ family now often had to make their meals of pumpkin instead of rice.)

(21) Yang guizi zenyang jiu pian le qian qu, Lao Tong $\mathrm{Bao}_{1}$ bu hen mingbai. Dan $\mathrm{ta}_{1}$ foreign devil how just scam AM money PA Old Tong Bao not very clear but he hen xiangxin Lao Chen Laoye de hua yiding bucuo. Bingqie taziji $1_{1}$ ye mingmingkandao very believe Old Master Chen MM word surely right and yet himself also quite plain see zicong zhenshang you le yang sha, yang bu, yang you, zhe yi lei since market town appear PA foreign cambric foreign cloth foreign oil this one CL yang huo, erqiehe li gengyou le xiao huolunchuan yihou, taziji foreign goods yet canal LOCeven appear PA small foreign boat after his own tian li shengchu lai de dongxi jiu yi tian yi tian bu zhiqian, er zhenshang de field LOCgrow PA RM things suddenly day by day not worth money and market town MM dongxi que yi tian yi tian gui qilai.

things yet day by day expensive PA

(How the foreign devils had accomplished this, Old Tong Bao ${ }_{1}$ wasn't too clear. $\mathrm{He}_{1}$ was sure, however, that Old Master Chen was right. Some things he himself $f_{1}$ had seen quite plainly. From the time foreign goods-cambric, cloth, oil - appeared in the market town, from the time the foreign river boats increased on the canal, what he ${ }_{1}$ produced brought a lower price in the market every day, while what he had to buy became more and more 
expensive.)

In (19), "taziji" (himself) in the last clause is coreferential with "ta" (he, viz. Old Tong Bao) in the preceding clause. In (20), "taziji" (in the last sentence) and its antecedent are separated by a subject-predicate structure; in other words, the antecedent comes two clauses backward in the discourse. In (21), "taziji" is used twice: the first is separated from its antecedent by one intervening (embedded) clause, and the second is much farther away from its antecedent. In those discourses, "taziji" is used to emphasize and highlight the MDP entities, each of which is in contrast with its concomitant, namely, "fuqin" (father) in (19), "shijie" (world) in (20) and "Lao Chen Laoye" (Old Master Chen) in (21). Consider another instance:

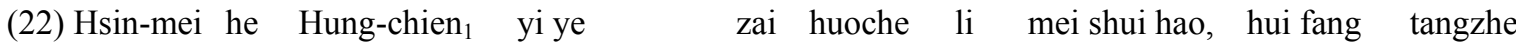

Hsin-mei and Hung-chien the whole nighton train LOCnot sleep well return room lie

xiuxi, Li Mei-ting 2 da men jinlaile, wen you shenme hao dongxi gei ta kan.

rest Li Mei-ting knock door enterAM ask have what fine things show him

Liangren $_{1} \quad$ lan qichuang, jiao taziji $\left(\mathrm{ta}_{2} / * \mathrm{ziji}_{2}\right)$ kan qiangbi shang de wenxian.

both of them not feel like getting up let himself (him/self) look at wall LOC MM graffiti

(Hsin-mei and Hung-chien ${ }_{1}$ hadn't slept well the whole night on the train, so they returned to their rooms to rest. $\mathrm{Li}_{2}$ knocked on the door and entered, asking them what wonderful things they had to show him. Neither of them 1 felt like getting up, so they let him $_{2}$ look at the wall graffiti by himself.)

Example (22) shows us more clearly the distinction between complex and simplex reflexive in Chinese: "liangren" (they both, namely Hsin-mei and Hung-chien) acts as the MDP in the current sentence where the reflexive appears; yet "taziji" is supposed to be understood as coreferential with "Li Mei-ting" in the prior sentence in the discourse; and therefore "taziji" may not be replaced by "ziji" though it can be replaced by a pronoun "ta". It is thus evidenced that a Chinese complex reflexive serves basically as an intensifier or highlighter in discourse.

All those discussed above are depicted by the pragmatic maxims stated in (8a-(i)) and/or (8b).

\section{Chinese Reflexives in Anaphoric Production}

Discourse anaphoric interpretation and production are two sides of a coin and can mirror one another. In what follows, we are to discuss and show from the perspective of speaker the fact that anaphoric production in Chinese discourse can be as well predicted and accounted for by our pragmatic principle.

The examples to describe the regular anaphora patterns in Chinese come from the data collected from both Chinese novels and English-Chinese translated novels. Analysis of these attested examples indicates that there are by and large two types of anaphoric production modes in Chinese discourse.

\subsection{Single-fold Anaphora}

The first type is referred to as single-fold anaphoric construction, which divides into three anaphoric patterns. They are characterized in order below.

Anaphoric pattern A: in a given (minimal) discourse where an NP (including pronoun, hereinafter inclusive) introduces the MDP, use or repeat using "ziji" (x) to encode and maintain this anaphoric relationship thus set up. The pattern is schematized in (23) and exemplified in (24)-(25).

(23) $\mathrm{NP}_{1} \ldots \quad \mathrm{x}_{1} \ldots \quad\left(\mathrm{x}_{1}\right) \ldots$

(24) a. Ma Xiansheng 1 zai Lundun sansi ge yue suo de de jingyan, bing bu suan Ma Mr. in London three-four CL month AU obtain RM experience can't be said

hen duo: zhaozhe le san si ge xiao Zhongguofanpu, tiantian qu chi dun wufan.

a lot find $\mathrm{AM}$ three-four $\mathrm{CL}$ small Chinese restaurant every day go eat CL lunch

$\mathrm{Ziji}_{1}$ neng buyong Ma Wei ling zhe, you puzi zou hui jia qu.

self may not need Ma Wei accompany AM from shop walk back home PA

(Mr. $\mathrm{Ma}_{1}$ couldn't really be said to have seen or done a lot in the three or four months that he'd been in London. He'd found a few Chinese restaurants where he would go for his daily lunch. And he $\mathrm{f}_{1}$ could find his way around without having Ma Wei; he usually walked home from the shop.)
b. $\mathrm{Ta}_{1}$
xihuan
nanfang, bingqie
ziji $i_{1}$ yiwei
hen kuai jiu cheng
le nanfang ren.
he like South and
self suppose
very soon then become
AM Southerner 
$\left(\mathrm{He}_{1}\right.$ liked the South, and he soon became, in his own ${ }_{1}$ opinion, a Southerner.)

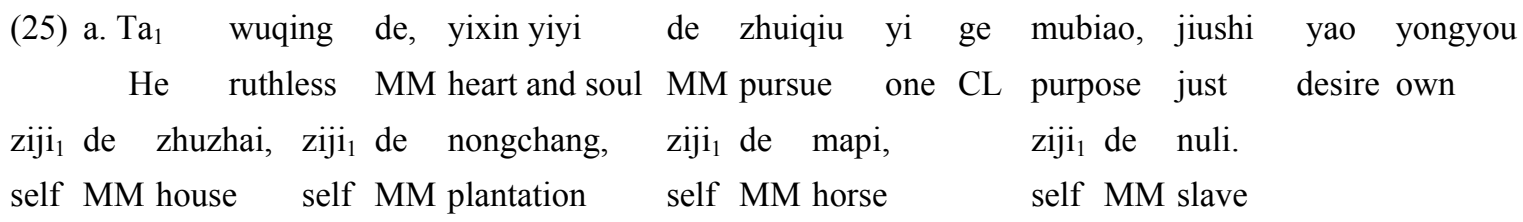

(With a ruthless singleness of purpose, he ${ }_{1}$ desired his own $n_{1}$ house, his own 1 plantation, his own horse, and his own $_{1}$ slaves.)

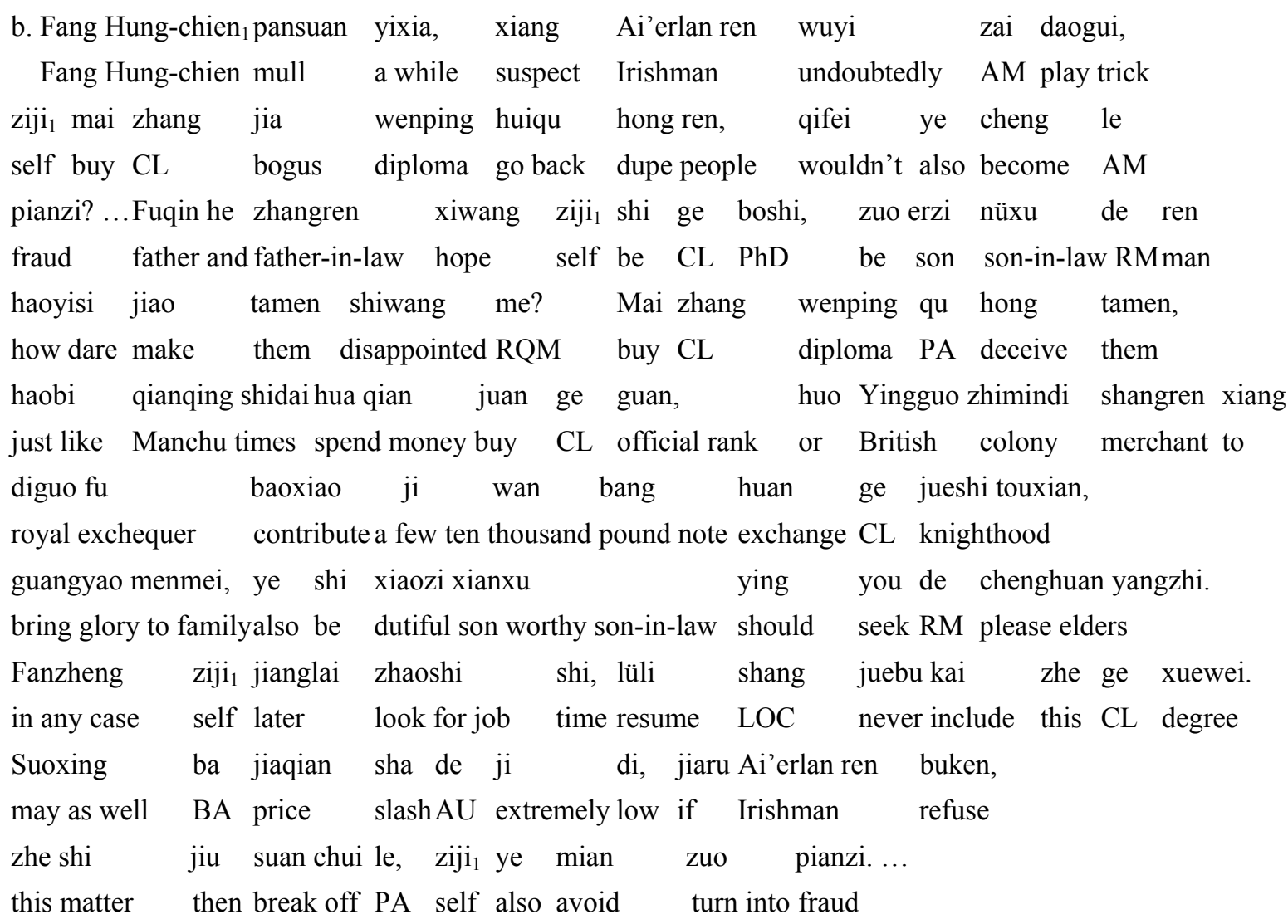

(Fang $_{1}$ mulled it over for a while, suspecting that the Irishman was undoubtedly up to tricks. If he $e_{1}$ bought a bogus diploma and went back to dupe other people with it, wouldn't he himself be a fraud? ... Since both his father and his father-in-law hoped he ${ }_{1}$ would become a Ph.D., how could he, a son and son-in-law, dare disappoint them? Buying a degree to deceive them was like purchasing an official rank in Manchu times, or like the merchants of a British colony contributing a few ten thousand pound notes to the royal exchequer in exchange for a knighthood, he reasoned. Every dutiful son and worthy son-in-law should seek to please his elders by bringing glory to the family. In any case, when later it came time for him 1 to look for a job, he would never include this degree in his resume. He might as well try slashing the price, and if the Irishman refused, he ${ }_{1}$ could then forget the whole thing and avoid turning into a fraud himself $f_{1}$.)

In each of the examples in (24), there is just one logophoric linkage encoded by "ziji"; and in the discourses of (25), "ziji" occurs in succession, forming an anaphoric/logophoric chain.

The anaphoric pattern in (23) has a variant, shown in (26): "ziji" is prepositioned so that a cataphoric pattern is made, namely, it is the case that the MDP comes forward (right) in the discourse. Such anaphoric patterns are more often than not observed to appear in complex or compound sentence constructions (like one with an independent clause followed or preceded by a dependent clause), including those conveying various logical relationships between the two clauses, such as temporal, cause-effect, condition-action, topic-comment, as shown in (27a-c).

(26) $\mathrm{x}_{1} \ldots \mathrm{NP}_{1} \ldots\left(\mathrm{x}_{1}\right) \ldots$

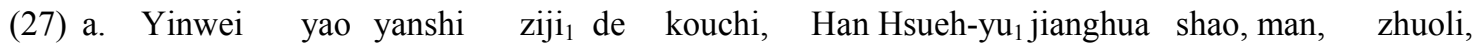
because wantcover self MM stuttering Han Hsueh-yu speak little slowly with great effort 
fangfu mei ge zi dou you ta quanbu renge as if each CL word totally by his entire personality

zuo danbao.

(In order to cover his ${ }_{1}$ stuttering, Han $_{1}$ spoke little, slowly and with great effort, as though each word carried with it the weight of his entire personality.)

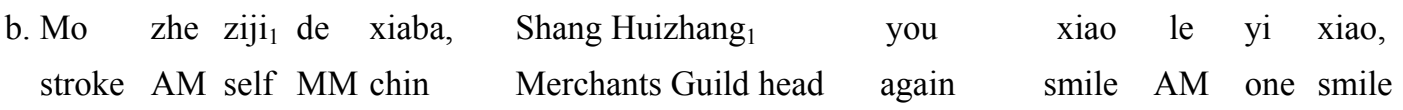
yu guo shenti lai shuodao:...

lean AM body PA say

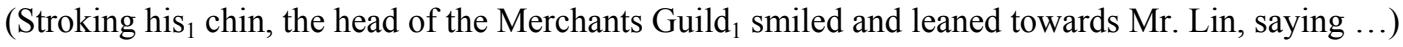

$\begin{array}{rlllllll}\text { c. Zhiyu } & \text { ziji }_{1} \text { jiali } & \text { de suoxie, } & \operatorname{ta}_{1} & \text { zhidao } & \text { Hung-chien } & \text { juebu } & \text { hui xiang } \\ \text { as for } & \text { self family } & \text { MM trifles } & \text { she know } & \text { Hung-chien } & \text { never } & \text { willto }\end{array}$

Fangjia qu jiang, zhe yi dian ta xiangxin de guo.

Fangs's family PA talk this one point she trust AU PA

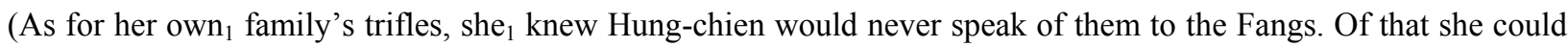
be sure.)

Anaphoric pattern B: in a given discourse where an NP introduces the MDP, alternately use "ziji" (x) and/or "Pr-ziji" (Pr-x) and/or Pr to encode and maintain this anaphoric linkage thus created. The pattern is schematized in (28).

(28) $\mathrm{NP}_{1} \ldots \quad \mathrm{x}_{1} / \operatorname{Pr}-\mathrm{x}_{1} / \operatorname{Pr}_{1} \ldots \quad \mathrm{x}_{1} / \operatorname{Pr}-\mathrm{x}_{1} / \operatorname{Pr}_{1} \ldots \quad\left(\mathrm{x}_{1} / \operatorname{Pr}-\mathrm{x}_{1} / \operatorname{Pr}_{1} \ldots\right)$

The anaphoric pattern in (28) says that when an NP (often lexical/full NP) is entered into the discourse, one may optionally make use of these three referential elements to establish and maintain the anaphoric relationship, and that the parenthesized $\operatorname{link}(\mathrm{s})$ is (are) optional (similar hereinafter). Thus as observed in the ensuing discourses, the anaphoric pattern in (29a) assumes an ' $\mathrm{NP}_{1}--\mathrm{X}_{1}-\mathrm{Pr}_{1}$ ' sequence; the one in (29b) ' $\mathrm{NP}{ }_{1}-\mathrm{Pr}-\mathrm{x}_{1}--\operatorname{Pr}-\mathrm{x}_{1}--\mathrm{x}_{1}$ '; and the one in (29c) ' $\mathrm{NP}(\operatorname{Pr})_{1}--\operatorname{Pr}-\mathrm{x}_{1}-\mathrm{x}_{1}--\operatorname{Pr}_{1}$ '.

$\begin{array}{rlllll}\text { (29) a. San Xiangu qixian } & \text { hai yiwei } & \text { ziji }_{1} \text { reng you gouyin } & \text { qingnian } & \text { de benling, } \\ \text { Third Fairy at first } & \text { still think } & \text { self still have lure } & \text { young man } & \text { RM ability } \\ \text { rizi chang le, qingnian } & \text { men bingbu } & \text { zhenzheng gen ta } \operatorname{ta}_{1} \text { jiejin. } & \\ \text { days long PA young man } & \text { PL not at all really } & \text { to her come close }\end{array}$

(Third Fairy ${ }_{1}$ as first thought her own ${ }_{1}$ charm was the cause. But gradually she saw it was the young men who were not really interested in her $_{1}$.)

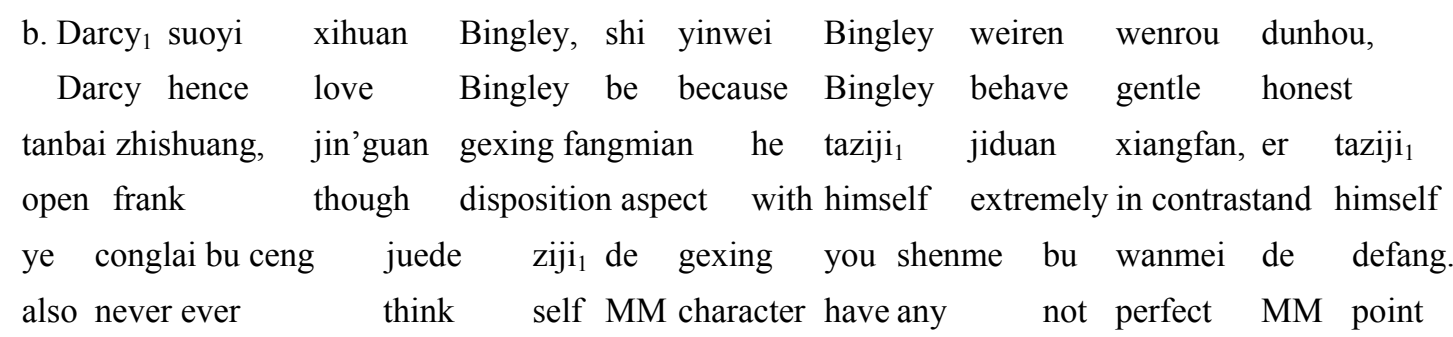

(Bingley was endeared to Darcy ${ }_{1}$ by the easiness, openness, ductility of his temper, though no disposition could offer a greater contrast to his $\mathrm{own}_{1}$, and though with his own $\mathrm{he}_{1}$ never appeared dissatisfied.)
c. $\mathrm{Ta}_{1}$ shuo:
hun le yibeizi
er mei chu guo jingmen, daodi
suan bu liao yingxiong,
he say live AM all life but not leave AM capital after all be not PA capable man

chengzhe hai you kou qi'er, qudao ge chu jianshi jianshi. Buguan zenyang, taziji

while still have CL breath come to various place have a look anyway himself

ye mei lian zai chenglihun, yinwei ziji de nü'er gei $\operatorname{ta}_{1}$ diu le ren.

also feel shameless in town stay because self MM daughter make him lose PA face

(If he never in his life left the capital, he ${ }_{1}$ said, he couldn't pride himself on being a man. While he still had breath in 


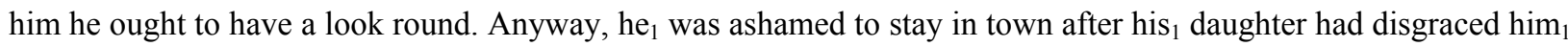
completely.)

Anaphoric pattern C: in a given discourse where an NP is used to introduce the MDP, alternately use "Pr-ziji" (Pr-x) and/or Pr to set up and/or maintain the anaphoric linkage thus created. Such an anaphoric pattern is given in (30), and it is exemplified by the discourses in (31). In (31a) the pattern is in ' $\mathrm{NP}_{1}--\mathrm{Pr}_{1}--\mathrm{Pr}_{-} \mathrm{x}_{1}$ ' sequence and in (31b) it is in ' $\mathrm{NP}_{1}-\mathrm{Pr}_{1}--\mathrm{Pr}-\mathrm{x}_{1}--\mathrm{Pr}-\mathrm{x}_{1}-\mathrm{Pr}_{1}--\operatorname{Pr}-\mathrm{x}_{1}$ ' sequence. The patterns described as such would be on a par with the prediction made by the pragmatic maxims in (8b-(i)/(ii)). That is, the anaphora pattern in (30) is triggered by the speaker's narration from an objective point of view and/or motivation to give emphasis and prominence to discourse entities.

(30) $\mathrm{NP}_{1} \ldots \quad \operatorname{Pr}-\mathrm{x}_{1} / \operatorname{Pr}_{1} \ldots \quad\left(\operatorname{Pr}-\mathrm{x}_{1} / \operatorname{Pr}_{1} \ldots\right)$

(31) a. Jane ${ }_{1}$ xinli you le kuaihuo de shiqing, xianglai bu yinman Elizabeth, yushi ta Jane in mind have PA pleasant MM thing always not keep fromElizabeth hence she mashang baozhu meimei, jiqi reqing de chengren taziji $1_{1}$ shi tianxia instantly embrace sister extremely lively MM acknowledge herself be in world zui xingfu de ren.

\section{mosthappy MM person}

(Jane ${ }_{1}$ could have no reserves from Elizabeth, where confidence would give pleasure; and (she ${ }_{1}$ ) instantly embracing her, acknowledged, with the liveliest emotion, that she $1_{1}$ was the happiest creature in the world.)

$\begin{array}{cllll}\text { b. Keshi, guanyu tamen dinghun de yaochuan, jiujing you shenme genju ne? } & \text { Zhe zhen } \\ \text { but regarding their engagement } & \mathrm{MM} \text { rumor at all have whatevidence RQM } & \text { This really }\end{array}$ jiao Elizabeth $_{1}$ wucong xiangxiang, houlai $\mathrm{ta}_{1}$ cai xiang qile Darcy jiu

let Elizabeth have no way imagine later she only recollect PA Darcy old

Bingley de hao pengyou, taziji $i_{1}$ shi Jane de meimei, er muqian dajia

Bingley MM goodfriend herself be Jane MM sister and now everybody

wangwang hui yinwei yi chong hunyin er liandai xiangdao zai jie yi chong

generally will because one CL wedding yet together think of again have one CL

hunyin, name, renmen ziran yao shengchu zhe zhong niantou laile. Taiziji

wedding then people naturally hopesupply this CL idea PA herself

ye zao jiu xiang daojiejie jiehun yihou, $\mathrm{ta}_{1}$ he Darcy jianmiande

also beforehand feel PA sister marry afterward she and Darcy meet RM

jihui ye jiu geng duo le. Yinci Lujianzhuang de linju men jing

chance also at once even more PA therefore Lucas lodge MM neighbor PL at all

ba zhe jian shi kancheng shi na jiu wen, erqie haosi jiu zai yanqian, keshi taziji

BA this CL matter set down as almost certain and as if just immediate but herself

zhibuguo juede zhe jian shi jianglai you dian xiwan eryi.

only think this CL matter at future time have a little hope and nothing more

(But from what the report of their engagement could originate, Elizabeth ${ }_{1}$ was at a loss to imagine; till she recollected that his being the intimate friend of Bingley, and her ${ }_{1}$ being the sister of Jane, was enough, at a time when the expectation of one wedding made everybody eager for another, to supply the idea. She ${ }_{1}$ had not herself $f_{1}$ forgotten to feel that the marriage of her sister must bring them ${ }_{1}$ more frequently together. And her neighbors at Lucas lodge, therefore, had only set that down as almost certain and immediate, which she ${ }_{1}$ had looked forward to as possible at some future time.)

\subsection{Multifold Anaphora}

The second type is referred to as dual or multifold anaphoric construction-different anaphoric chains made by two or more than two referring expressions which are disjoint in reference from one another. In some context of the discourse where two or more anaphoric chains are needed to construct, there is normally a distinct divide in the 
co-occurrences of the three referential elements in question, making up four situations: generally, (i) "ziji" (x) is used to refer to (the) MDP (entity) and a pronoun (Pr) other entity; (ii) "ziji" (x) is used to refer to MDP and "Pr-ziji" (Pr-x) other entity; (iii) "Pr-ziji" (Pr-x) is used to refer to MDP and a pronoun (Pr) other entity; or (iv) "ziji" is used to refer to MDP while "Pr-ziji" (Pr-x) and a pronoun (Pr) other entity or entities. The anaphora patterns corresponding to those four situations are schematized in (32a-d), where $\mathrm{NP}_{1}$ stands for the antecedent encoding $\mathrm{MDP}$, and $\mathrm{NP}_{2}\left(\mathrm{NP}_{3}\right.$, etc.) stands for other antecedent (or antecedents) encoding other entity (or entities).

(32) a. $\mathrm{NP}_{1} \ldots \mathrm{x}_{1} \ldots$ vs. $\mathrm{NP}_{2} \ldots \mathrm{Pr}_{2} \ldots$

b. $\mathrm{NP}_{1} \ldots \mathrm{x}_{1} \ldots$ vs. $\mathrm{NP}_{2} \ldots \operatorname{Pr}-\mathrm{x}_{2} \ldots$

c. $\mathrm{NP}_{1} \ldots \operatorname{Pr}-\mathrm{x}_{1} \ldots$ vs. $\mathrm{NP}_{2} \ldots \operatorname{Pr}_{2} \ldots$

d. $\quad \mathrm{NP}_{1} \ldots \mathrm{x}_{1} \ldots$ vs. $\mathrm{NP}_{2} \ldots \operatorname{Pr}-\mathrm{x} / \mathrm{Pr}_{2} \ldots$ (vs. $\left(\mathrm{NP}_{3} \ldots \mathrm{Pr}-\mathrm{x} / \mathrm{Pr}_{3} \ldots\right)$ )

Having got the patterns in (32) instantiated, it will be then natural for us to make it clearer that in Chinese discourse, (i) where "ziji" and a pronoun concur, the former is used to refer to MDP and the latter other entity, as in (33a); (ii) where "ziji" and "Pr-ziji" concur, the former is used to refer to MDP whereas the latter other entity, as in (33b); (iii) where "Pr-ziji" and a pronoun concur, the former is used to refer to MDP while the latter other entity, as in (33c); (iv) where "ziji" and "Pr-ziji" / a pronoun (or alongside a third "Pr-ziji"/pronoun) concur, the former is utilized to refer to MDP and the latter (or a third item) other entity (or a third entity), as in (33d).

(33) a. Jane ${ }_{2}$ de bing hai bu jian haozhuan, Elizabeth ${ }_{1}$ cun bu bu li Jane MM disease still not appear improve Elizabeth closely huanghun,kanjian $\mathrm{ta}_{2}$ shuizhao le, cai fangxia le xin, juede ziji yinggai dao evening see her asleep AM then set as rest PA mind feel self should go louxia qu yi tang.

downstairs PA one time

(She ${ }_{2}$ was still very poorly, and Elizabeth ${ }_{1}$ would not quit her ${ }_{2}$ at all till late in the evening, when she ${ }_{1}$ had the

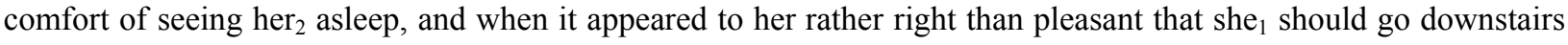
herself ${ }_{1}$.)

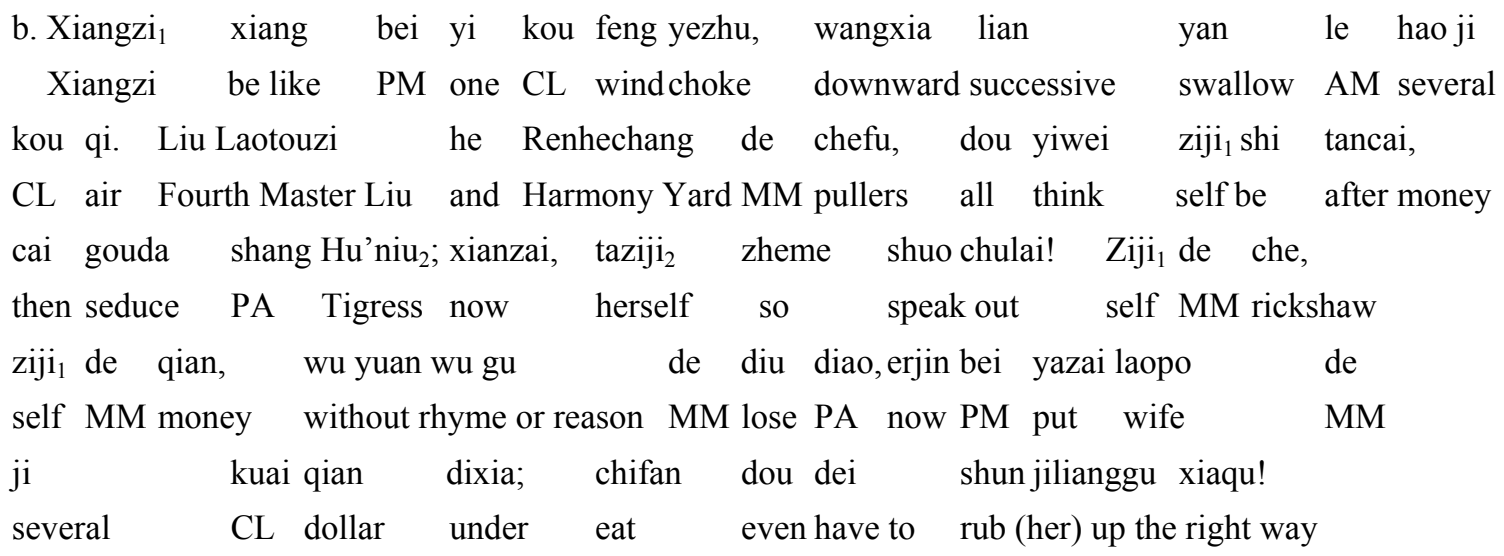

(Xiangzi $i_{1}$ felt as if choked by a gust of wind and swallowed several times. Fourth Master Liu and the pullers at the yard had all thought he $e_{1}$ was after money when he took up with Tigress 2 , and now here she $e_{2}$ was accusing him of the same thing! Without rhyme or reason he had lost his own ${ }_{1}$ rickshaw and his ${ }_{1}$ money. His wife's few dollars put him under her thumb - even to eat he had to rub her up the right way!)

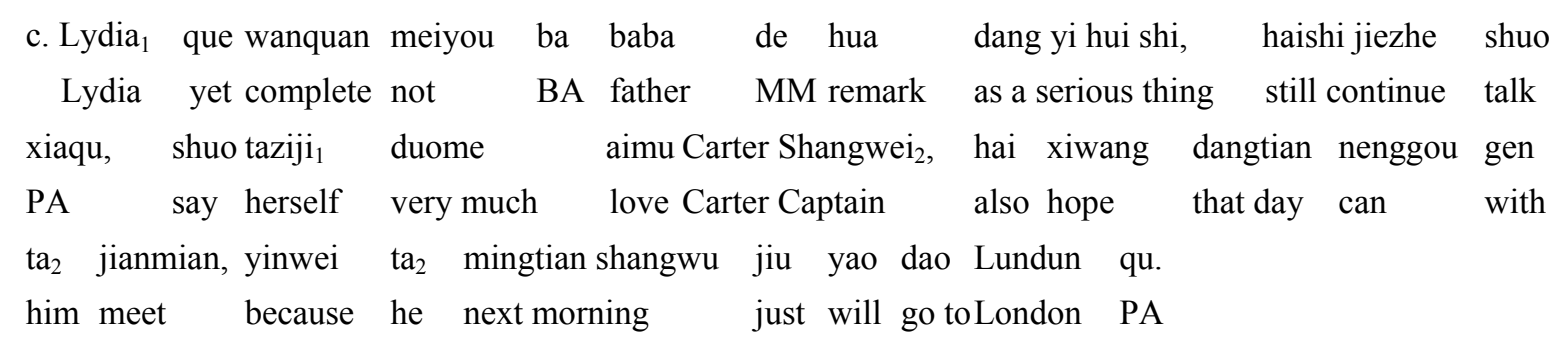

(Lydia ${ }_{1}$, with perfect indifference, continued to express her ${ }_{1}$ admiration of Captain Carter $_{2}$, and her hope of seeing 
$\operatorname{him}_{2}$ in the course of the day, as he $\mathrm{e}_{2}$ was going the next morning to London.)

d. Gao Song-nian $_{1}$ wen xun congcong dao jiaoyuan susheli yingchou yixia, hui dao bangongshi,

Gao Song-nian learn of it hurry over to teacher dormitory give greeting once return to office

yi yue lai de xinshibu neng zai ge zai yibian bu xiang le. Zicong Changsha
one month since MM matter can no longer put aside not meditate PA since Changsha weiji, pin hao de jiaoshou li shi ge daoyou jiu ge dadianbao lai tuo gu crisis hire PA RM professor of ten CL yet nine CL send telegram PA on pretext jie yue, qi ling ba luo, kai bu chu ban, xing'er xuesheng ye shou zhanshi yingxiang, cancel contrast topsy-turvy cannot begin class luckily students also get war influence zhiyou 158 ren. Jintian yi lai jiu shi si ge jiaoshou, junrong da zhen, only 158 student today at once arrive exactly four CL professor real boost to morale xiang buli bao shang ye timian xie. Zhishizenyang dui Li Mei-ting to Education Ministry report PA also look better a little but how to Li Mei-ting he Fang Hung-chien jieshi ne? Buli Wang Cizhang jieshao and Fang Hung-chien explain RQM Education Ministry Wang Vice-minister recommend Wang Chu-hou lai dang ZhongguoWenxuexi zhuren, ziji zao xiexin pin Wang Chu-hou PA be Chinese Literature Department chairman self already write appoint ding Li Mei-ting 2 liao, keshi Wang Chu-hou shi Wang Cizhang de bofu, lun definite Li Mei-ting PA but Wang Chu-hou be Wang Vice-minister MM uncle regarding zige ye bi Li Mei-ting hao, na shihou gei jiaoshou luxu chi pin de qualification also than Li Mei-ting better that time PM professor successive decline appointment RM dianbao xia hun le tou, pa Shanghai zhe pi ren hui da hui piao, telegram scare stunned PA head afraid Shanghai this group people will turn back halfway zhihao xian fuyan Cizhang. Wang Chu-hou zhe ren bu hao dafa, Li Mei-ting ${ }_{2}$ shi lao only first humor Vice-ministerWang Chu-hou this man not easily handle Li Mei-ting be old pengyou, lao pengyou zongjiang de kai, jiu pa $\mathrm{ta}_{2}$ de piqi nan duifu! friend old friend always be brought around just worry his MM temper hard deal with Zhe xing Fang de nian qing ren ${ }_{3}$ dao rongyi duifu de. $\mathrm{Ta}_{3}$ shi Chao Xin-mei de laitou, this young Fang fellow should easy handle PA he be Chao Xinmei MM friend Xin-mei zuichu bu ken lai, jieshao le $\mathrm{ta}_{3}$, shuo ta $\mathrm{a}_{3}$ shi liuxue Deguo Xin-mei at first not want come recommend PA him say he be study abroad Germany de boshi, zhenhutu touding! Taziji ${ }_{3}$ kai lai de xueli, bing meiyou xuewei, RM doctor real nonsense absolutelyhimself send PA RM resume yet have no degree zhi shi ge ge guo langdang de liuxuesheng, bingqie bingfei xue zhengzhi de, only be CL various countrydissipate RM student drifter and even never study politics RM pin ta $_{3}$ dang jiaoshou tai yuanwangle! Zhiduo zuo fu jiaoshou, xun xu jian jin, hire him as professor too unjust PA at most start as associate prof. work up step by step nian qing ren chu zuo shi bu yinggai pa de tai gao, zhe hua keyi jiao Xin-mei young people first do job shouldn't climb AU too high this can have Xin-mei dui $\mathrm{ta}_{3}$ shuo. Weinan de hai shi Li Mei-ting ${ }_{2}$. Wulunruhe, $\mathrm{ta}_{2}$ qian xin wan $k u$ lai le, to him say difficult MM still be Li Mei-ting in any case hethru many hardship come PA juebu hui yi fanlian jiu zou de; lai de kunnan, qu ye mei name never will just break off mad leave immediately PA come AU difficult leave also not so 


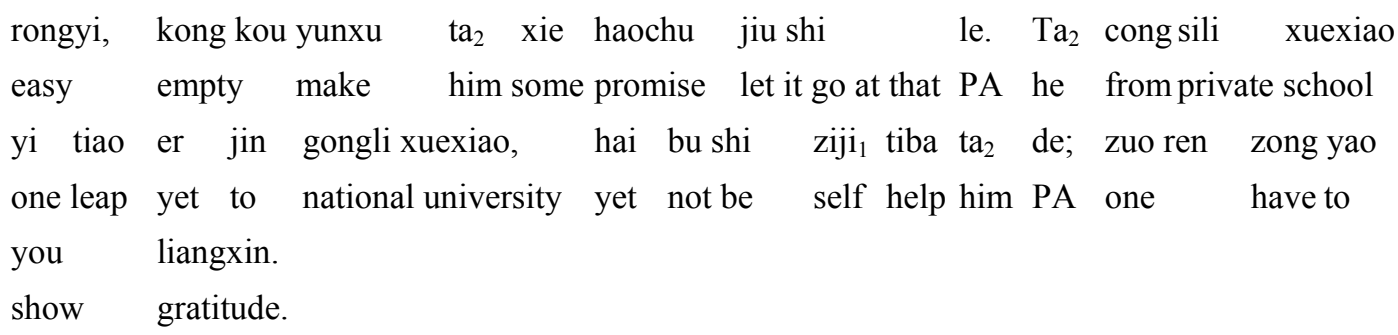

$\left(\mathrm{Kao}_{1}\right.$ hurried over to the faculty dormitory to greet them; then returned to his office, no longer able to dismiss matter that had been troubling him for the past month. Since the crisis at Changsha, nine out of ten professors he hired had sent telegrams canceling their contracts on one pretext or another. Everything was topsy-turvy and many classes had to be canceled; fortunately, the war had affected the students also, and only 158 of them had shown up. Having four professors arrive all at once was a real boost to his morale, and it would look a little better when he wrote a report to the Ministry of Education. But how was he to explain things to Li Mei-ting and Fang Hung-chien? Vice-minister Wang of the Ministry of Education had recommended Wang Chu-hou to be chairman of the Department of Chinese Literature. Meanwhile he $\mathrm{H}_{1}$ had already written and appointed Li Mei-ting ${ }_{2}$ to the post- - but Wang Chu-hou was Vice-minister Wang's uncle and for that reason was better qualified than Li Mei-ting. The succession of telegrams from professors declining appointments at that time had put his head in a spin. Afraid that the group from Shanghai would turn back halfway, he decided he had better humor Vice-minister Wang first. He felt Wang Chu-hou could not be easily handled, while Li Mel-ting 2 was an old friend and as such could always be brought around. He $\mathrm{H}_{1}$ was worried that Li's ${ }_{2}$ temper would be hard to deal with. Very hard indeed! That young Fang fellow $_{3}$, on the other hand, should be easy to handle. Fang 3 was a friend of Chao Hsin-mei. Not wanting to come himself, Hsin-mei had at first recommended Fang 3 , saying Fang 3 was a returned student with a doctorate from Germany. What absolute nonsense that was! According to the resume sent by Fang himself ${ }_{3}$, Fang had no degree at all and was nothing but a student drifter who had led a life of dissipation in one country after another. Furthermore, Fang had never even studied political science. To hire Fang 3 as a professor would be an injustice! At the most Fang could start as an associate professor and work his way up step by stop. Young people shouldn't climb too high in their jobs. He could have Hsin-mei tell Fang 3 that. The difficult still lay with Li Mei-ting ${ }_{2}$. In any case, $\mathrm{Li}_{2}$ had been through hell and high water to get here, so Li certainly wouldn't just break off mad leave immediately. Since getting here had been so difficult, leaving wouldn't be so easy either. $\mathrm{He}_{1}$ would make $\mathrm{Li}_{2}$ some empty promises and let it go at that. After all, wasn't it through his ${ }_{1}$ influence that $\mathrm{Li}_{2}$ had made it from a private school to a national university in one leap? One had to show some gratitude.)

To summarize, those textual examples evince a nearly undeniable pragmatic theorem: all other conditions being equal, in the production of dual/multifold discourse anaphora in Chinese, the speaker (writer/translator) almost always tend to use "ziji" to refer to the MDP, and use the other two reference forms (i.e. complex reflexive and pronoun) to refer to other entities in the discourse. This phenomenon results from the fact that "ziji" does nearly always serve to be logophoric in discourse (Liu 2008b: 34-35). Those anaphoric production modes so far discussed can be all captured by the supplementary maxim of production, stated in (8b-(iii)).

\section{Concluding Remarks}

As seen from this article, we have formulated as our analytic framework a pragmatic principle capturing anaphora patterns in discourse, in light of some relevant theoretical notion in the literature; and with it we have described ad hoc the functions of third-person reflexives in Chinese. Our detailed description and analysis shows that in Chinese discourse, a simplex reflexive basically functions logophorically whereas a complex one, which is treated as an intensive item of pronoun, serves primarily to highlight and contrast entities in the discourse.

Our discussion further shows that there are two types of anaphoric production modes: one bears a single anaphoric chain and the other bears two or more than two anaphoric chains. It can be inferred from the study that the anaphora patterns in Chinese are very possibly more complicated than those in English since there is a system of simplex and complex reflexive in Chinese. Overall, the anaphoric interpretation and production in Chinese discourse can be effectively captured by the pragmatic principle proposed in this paper.

Abbreviations

The abbreviations below are used in the glosses of the Chinese examples.

AM aspectual marker

AU auxiliary: e.g. de used after a verb/adjective as in a resultative clause, suo used before a verb in an attributive clause indicating the head is patient, or laizhe used after the predicate indicating what has just 


\section{happened}

BA the causative preposition ba in ba-construction

CL classifier

LOC locative

MM modifier marker: de (including possessive de)

PA particle: e.g. lai, qi or qilai used after a verb indicating starting to do something; guo used after the auxiliary de (as in ' $v+d e+$ guo'), and hao / shang / qu after a verb, indicating completing some action; de, dao, diao, le, liao (as in ' $v+b u+$ liao') or qilai after a verb (or adjective), or laile used at the end of a sentence, indicating the result of an action

PL plural

PM passive marker: including bei, gei and you

RM relativized marker

RQM rhetorical question marker

\section{References}

Baker, C. L. (1995). Contrast, discourse prominence, and intensification, with special reference to locally free reflexives in British English. Language, 71, 63-101. http://dx.doi.org/10.2307/415963

Baltin, M. (2003). The interaction of ellipsis and binding: Implications for the sequencing of Principle A. Natural Language and Linguistic Theory, 21, 215-246. http://dx.doi.org/10.1023/A:1023342528033

Battistella, E., \& Xu, Y. (1990). Remarks on the reflexives in Chinese. Linguistics, 28, 205-240

Culy, C. (1994). Aspects of logophoric marking. Linguistics, 32, 1055-1094. http://dx.doi.org/10.1515/ling.1994.32.6.1055

Halliday, M. A. K., \& Husan, R. (1976). Cohesion in English. London: Longman.

Halliday, M. A. K., \& Matthiessen, Christian M. I. M. (2004). An Introduction to Functional Grammar (3rd edition). London: Edward Arnold.

Hoeksema, J., \& Napoli, D. J. (1990). A condition on circular chains: A restatement of i-within-i. Linguistics, 26, 403-424

Huang, C. T. J., \& Tang, C. C. J. (1991). The local nature of the long-distance reflexive in Chinese. In J. Koster \& E. Reuland (Eds.), Long-distance Anaphora. Cambridge: Cambridge University Press, pp. 263-282. http://dx.doi.org/10.1017/ CBO9780511627835.014

Huang, Y. (1994). The Syntax and Pragmatics of Anaphora: A Study with Special Reference to Chinese. Cambridge: Cambridge University Press.

Huang, Y. (2000). Anaphora: A Cross-linguistic Approach. Oxford: Oxford University Press.

Huang, Y. (2008). Anaphora, generative grammar and neo-Gricean pragmatics (lecture). Guangdong University of Foreign Studies, Guangzhou.

Liu, L. (2008a). The anaphoric function of the reflexive "ziji" in modern Chinese. Foreign Languages, 1, 36-44

Liu, L. (2008b). A cognitive-functional perspective on intensive reflexives in English and Chinese. Foreign Language Teaching and Research, 1, 29-36

Reinhart, T., \& Reuland, E. (1991). Anaphors and logophors: An argument structure perspective. In J. Koster, \& E. Reuland (Eds.), Long-distance Anaphora. Cambridge: Cambridge University Press, pp. 283-321. http://dx.doi.org/10.1017/ CBO9780511627835.015

Reuland, E. (2009). Binding theory. Downloaded from the Internet (Oct. 7, 2009).

Sells, P. (1987). Aspects of logophoricity. Linguistic Inquiry, 18, 445-479

Xu, L. (1997). Linguistic theories and linguistic facts. Modern Foreign Languages, 3, 26-32

Xu, Y. (2004). Towards a Functional-pragmatic Model of Discourse Anaphora Resolution. Shanghai: Shanghai Foreign Language Education Press.

Zribi-Hertz, A. (1989). Anaphor binding and narrative point of view: English reflexive pronouns in sentence and discourse. Language, 65, 695-727. http://dx.doi.org/10.2307/414931 


\section{Notes}

Note 1 . We do not include in principle first and second person reflexives in this article, given the fact that most linguists tend to take a negative view of the endophoric/anaphoric use of first and second person pronouns including reflexives. For example, Hoeksema and Napoli (1990: 422) note that first and second person pronouns are always interpreted deictically. Also, Halliday and Hasan (1976: 18) and Halliday and Matthiessen (2004: 551) claim that "first and second person pronouns as speech roles of speaker and addressee, are typically exophoric and secondarily anaphoric (speaker and addressee in quoted speech); ... This type of reference we call EXOPHORA, since it takes us outside the text altogether. Exophoric reference is not anaphoric, since it does not bind the two elements together into a text."

Note 2. Given the complexities in actual discourse, in this paper we do not consider the case of 'zero pronoun'.

Note 3. We acknowledge that part of the interpretation maxims in (8a) is adapted from Zribi-Hertz's (1989) "discourse principle", despite the fact that there is not at all any complete, mechanical clone made of the latter.

Note 4. A comparison of the semantic information given in $(5 a) /(5 b) /(6)$ obviously shows that: a) "Pr-ziji" is richer in contrastive and emphatic information than "ziji"; b) a pronoun carries the feature [-Log], suggesting that its use is motivated by an objective point of view taken by the speaker in narration.

Note 5. Besides, we argue that there is a stricter restriction, the so-called 'animacy' and/or 'consciousness' constraint, on the use of reflexives: as antecedent, any MDP entity is supposed to be animate or conscious. In this discourse, "Liang" as MDP is now an inanimate entity, disallowing use of a reflexive.

Note 6. The textual examples in Chinese and their translations in parenthesis hereafter all come from the data we collected from the Chinese and English novels and their equivalently translated ones. For simplicity, only the names of the novels with the authors/translators are listed here (rather than given at the end of each example): A. Chinese novels and their translations: 1) Qian Zhongshu, Wei Cheng. Jeanne Kelly and Nathan K. Mao (transl.), Fortress Besieged; 2) Lao She, Luotuo Xiangzi. Shi Xiaojing (transl.), Camel Xiangzi; 3) Lao She, Erma. Julie Jimmerson (transl.), Mr. Ma \& Son, a Sojourn in London; 4) Mao Dun, Linjia Puzi / Chun Can. Sidney Shapiro (transl.), The Shop of the Lin Family / Spring Silkworms; 5) Lao She and Others / Yu Bingqing (ed.), Zhongguo Xiandai Mingjia Duanpian Xiaoshuo Xuan. Sidney Shapiro (transl.), Masterpieces by Modern Chinese Fiction Writers. B. English novels and their translations: 1) Jane Austin, Pride and Prejudice. Wang Keyi (transl.), Aoman Yu Pianjian; 2) Margaret Mitchell, Gone with the Wind. Chen Liangting and others (transl.), Luanshi Jiaren. 